\title{
The Challenges and Countermeasures of Realizing the Modernization of Government Network Public Opinion Management in the Age of Big Data
}

\author{
Jin $\mathrm{Yi}$ \\ ${ }^{1}$ College of Politics and History, Bohai University, Jinzhou, P.R.China \\ ${ }^{2}$ Political science Postdoctoral Scientific Research of Tianjin Normal University, Tianjin, P.R.China \\ jinyilixiang@163.com
}

Keywords: the era of big data, network public opinion, online public opinion governance.

\begin{abstract}
Internet public opinion in the era of big data has "predictability." The government's network public opinion governance is mainly faced with the challenges of public opinion analysis technology, the quality of public opinion data, the lack of publicity and sharing of public opinion data, the lack of the ability of public opinion governance, the imperfect public opinion laws and regulations, and the inadequate protection of public opinion data rights. To this end, it is necessary to strengthen the support of big data technology for public opinion governance, improve the level of network public opinion guidance, strengthen the multi-subjects' cooperative management, continuously improve the government's ability to "operate the network", promote the open sharing of government affairs information, promote the expression and dialogue of online public opinion, and improve the mechanism of governance network according to law, implement the accountability of network public opinion governance, in order to achieve the modernization of government network public opinion governance.
\end{abstract}

\section{1. the new characteristics of network public opinion development in the era of big data}

Internet public opinion is the mapping and direct reflection of social public opinion in the Internet space. It is based on the network, with public affairs, social hotspots and network topics as the core, the expression, communication and interaction of the emotions, attitudes, and opinions of the majority of netizens', and the follow-up collection of subsequent influences. It has the characteristics of instant suddenness, significant impact, diversification of information carriers, dissemination and diffusion, and behavioral secularity.

Internet public opinion in the era of big data has "predictability." The application and development of big data technology can provide support for network public opinion governance, so that "social public opinion monitoring and analysis, early warning decision-making, emergency response and guidance are analyzed from what happened in the past and why it happened, to grasp what is happening now, and then It is possible to predict what will happen in the future and to make automated decision output."[1]

2. the main challenges faced by government network public opinion governance in the era of big data

\subsection{Public opinion analysis technology needs to be enhanced, and the quality of public opinion data is mixed}

At present, the update speed of information technology such as big data and cloud computing in China is relatively slow, and the security is not high enough. The big data technology in the whole country has not been popularized, and the utilization rate is relatively low. Data dispersal, public opinion data monopoly and data barriers are still serious, public opinion monitoring technology is relatively backward, technical monitoring process has yet to be improved, and timeliness is not strong. 
In addition, in the process of information processing, because the integration of the network information source is not enough, the acquisition algorithm is relatively simple, and it is inevitable that some irrational factors will be mixed, resulting in the information collection presents repetitive, non-correlated and superficial. The lack of intelligence in some public opinion analysis processes has resulted in often mixed data and compromised data quality.

\subsection{The publicity and sharing of public opinion data is insufficient, and the ability to control public opinion is not strong}

At present, the comprehensiveness of information disclosure in China is obviously insufficient, and the accuracy and timeliness of information need to be improved. Some government websites are backward in analysis technology and cannot perform accurate analysis and quantitative management. There are lack of special government data opening and licensing policies, "The relevant provisions on information and data security and personal information protection are scattered among many laws, regulations and policies. The reason for the protection of security and privacy is often the reason for the government to refuse information disclosure. [2] Also, there are information silos, digital barriers, and data chimneys in some places.

In the process of public opinion governance, some government departments and officials can not actively collect online public opinion information, or analyze and judge the public opinion information is too emotional, subjective, lack of scientific, solid, quantitative, and comparable data foundation, it is difficult to accurately grasp the public opinion situation in time. Some officials are accustomed to making a brief statement about the surface content of the lyric events, lacking in-depth information dissemination, or even if the publication is unclear, or deliberately concealing the truth, it is difficult to meet the public's informed needs. Some officials have not responded promptly to the Internet public opinion, administrative inaction, and lost the sensation to guide the initiative. Some officials intentionally control and block messages, block public opinion expression, and even take strong control of broken machines or violent machines.

\section{3 the public opinion governance system is not perfect, the data protection is insufficient}

At present, the legislative level of network public opinion governance is relatively low, the relevant laws and regulations are not rigid, and there is lack of targeted, systematic, authoritative and coordinated. The system of public opinion collection, research and judgment, online public opinion response and public opinion governance is imperfect. The administrative accountability and return mechanism of illegal and dereliction of duty officials is relatively vague and general, and the accountability of officials has quietly reappeared.

At the same time, the ownership, use rights and disposal rights of public opinion data collected by big data technology, as well as the openness and openness of public opinion data are not clear enough. In the process of collecting and using public opinion, there is a violation of personal data privacy and rights.

\section{3. the path to achieve the modernization of government network public opinion governance in the era of big data}

\subsection{Strengthen the public opinion data management support for public opinion and improve the level of public opinion guidance}

Actively expand access to public opinion data, construct a rich basic database and public opinion big data platform, and build a central hub for data storage and exchange as soon as possible: network big data center, break the "data island" of all walks of life, and achieve rapid data collection, standardized management and efficient use. Actively develop and update public opinion management software, establish a collection, analysis and evaluation index system for public opinion data, formulate a unified data interface standard, and improve the technical support capability of big data for network public opinion. 
Actively carry out research and innovations in key technologies such as data monitoring, storage, mining, analysis, and security. Using the powerful "correlation analysis" capability of big data, organically integrate online and offline effective data, and build a three-dimensional network public opinion data information network. Improve the technology of data storage and analysis, efficiently read, write and exchange public opinion information, accurately analyze the dynamics of public opinion, grasp the operating rules and development trends of public opinion, and effectively improve the security, accessibility and representation of big data public opinion. Vigorously cultivate network public opinion analysts and informants, closely track and analyze public opinion information, and explore the laws and trends of its occurrence and development.

Make full use of big data to establish and improve the network public opinion analysis system, fully present the ins and outs of public opinion events, timely respond to and clarify possible information distortions and network rumors, effectively improve the appeal and persuasiveness of public opinion guidance. Strengthen the construction of mainstream news websites and establish the authority of government information dissemination. Multi-channel training of network opinion leaders with mainstream social identity, and actively strive for online discourse power. Establish a rapid response mechanism and a network security emergency work mechanism, strengthen the joint management organization for emergency management and public opinion incidents, and organize regular drills, improving the ability of the government to control public opinion.

\subsection{Strengthening the coordinated management of sensational multi-subjects and continuously improving the government's ability to "operate"}

Strengthening the multi-subject collaborative management of network public opinion, so that the government, network enterprises, netizens, network NGOs and other subjects, under the premise of mutual trust, motivate the common interests to promote the optimal use of advanced resources, spontaneously form mutual promotion, A self-organizing collaborative governance structure that combines points and surfaces, is highly ordered, and maximizes the realization of public interest. In the network public opinion governance, it realizes policy coordination in decision-making interest coordination, resource coordination in decision-making execution, and governance effectiveness guarantee.

Actively use big data to grasp the development status and changing rules of network public opinion, accurately predict the development trend of online public opinion, continuously improve the scientific, pertinence and effectiveness of public opinion governance, and improve the network public opinion information collection ability, and the ability of public opinion identification rapid response, communication and coordination, network governance of network managers.

\subsection{Promote the open sharing of government affairs information and promote the expression of online public opinion dialogue}

The government's open data is an important indicator of the in-depth development of government information disclosure. In the era of big data that "everything can be quantified", we should make full use of big data technology to break the division of government departments, data monopoly and "information silos", build cross-media platform, cross-departmental regional connectivity mechanism, establish a unified and integrated government data portal and shared network group system, and promote the convergence and sharing of government data resources. Timely understand and grasp the pulsation of online public opinion information, provide timely, comprehensive and reliable information to the public in accordance with the law, to meet the public's right to know.

Adapting to the current network public opinion expression in China has entered the new Internet environment of the mobile Internet era, build an institutionalized interactive platform of government and people to support and encourage citizens to express their rights and interests. Promote online public opinion response mechanism by establishing and improving online government-civilian interaction mechanism, government and media information linkage mechanism, network news spokesperson mechanism, effectively improve the efficiency and effectiveness of government online 
public opinion response. Pay attention to the construction of network negotiation mechanism based on negotiation, dialogue and discussion, so as to effectively resolve conflicts of interests.

\subsection{Improve the mechanism of network governance according to law and implement the accountability of network public opinion governance}

Accelerate the process of data legislation and law enforcement, improve the system of laws and regulations on network public opinion governance, and clarify the rights and obligations of governments at all levels and Internet companies to provide and share relevant public opinion data to network data centers. The management made detailed regulations for collecting, distributing, storing, analyzing, and using data, resolutely cracked down on cybercrime such as illegal network public relations and manufacturing and communication network rumors, creating a healthy and orderly network environment. Strictly abide by the "Network Security Law of the People's Republic of China", establish and improve the network security review system, prevent network product providers from taking the opportunity to illegally control, interfere with, interrupt user systems, and illegally collect, store, process and utilize user-related information. Strengthen the propaganda and education of network laws and regulations, vigorously improve the citizen's subjective consciousness and network literacy, and cultivate rational and mature lyrical expression subjects. It is necessary to build a rumor information database, improve search engine technology and information push services, construct a full-media terminal, optimize the deep rumor function, media literacy education function and rumor self-purification function, and construct and improve the all-media rumor platform. [3]

Accelerate the construction of network culture and credit system, strengthen the self-discipline construction of the media industry, and build a media clearance mechanism. It is necessary to improve the accountability mechanism and protection mechanism of online public opinion governance, and to conduct timely and effective accountability for those who are deceiving, delaying, and dereliction of duty.

\section{Acknowledgement}

This research was financially supported by Bohai University's practical (progressive) project "Strategic research on strengthening the public opinion governance of the province in the era of big data" and the special topic of "Xi Jinping's New Era of Socialism with Chinese Characteristics" in Bohai University "Study on enhancing and improving the network ideology work of the university in the new era ".

\section{References}

[1] Cai Lihui, Yang Xinyu. Application of Big Data in Social Public Opinion Monitoring and Decision Making[J]. Administration Forum, vol. 2, pp. 1, 2015.

[2] Delia. Government data open research under the big data environment [M]. Intellectual Property Press, pp. 88, 2014.

[3] Xu Hongyan, Jin Yi. Analysis of the practice and application of the all-media platform in China. China publishing journal, vol. 20, pp. 32, 2017. 